\title{
A method to retrieve super-thin cloud optical depth over ocean background with polarized sunlight
}

\author{
W. Sun ${ }^{1,6}$, R. R. Baize ${ }^{2}$, G. Videen ${ }^{3,4}$, Y. Hu${ }^{2}$, and Q. Fu ${ }^{5}$ \\ ${ }^{1}$ Science Systems and Applications Inc., Hampton, VA 23666, USA \\ ${ }^{2}$ Science Division, NASA Langley Research Center, Hampton, VA 23681, USA \\ ${ }^{3}$ Space Science Institute, Boulder, CO 80301, USA \\ ${ }^{4}$ Army Research Laboratory, Adelphi, MD 20783, USA \\ ${ }^{5}$ Department of Atmospheric Sciences, University of Washington, Seattle, WA 98195, USA \\ ${ }^{6}$ Mail Stop 420, NASA Langley Research Center, Hampton, VA 23681, USA \\ Correspondence to: W. Sun (wenbo.sun-1@nasa.gov)
}

Received: 21 July 2015 - Published in Atmos. Chem. Phys. Discuss.: 13 August 2015

Revised: 9 October 2015 - Accepted: 17 October 2015 - Published: 27 October 2015

\begin{abstract}
In this work, an algorithm that uses the polarization angle of the backscattered solar radiation to detect clouds with optical depth (OD) $<\sim 0.3$ is further developed. We find that at viewing angles within $\pm \sim 8^{\circ}$ around the backscattering direction, the $p$-polarized intensity that is parallel to the meridian plane of reflected light from the surface is sensitive to, and nearly linearly related to, the optical depth of super-thin clouds. Moreover, our sensitivity study suggests that the $p$-polarized intensity at these viewing angles is not sensitive to the ocean surface conditions. Using this property of $p$-polarized intensity, super-thin clouds' optical depth can be retrieved.
\end{abstract}

\section{Introduction}

Super-thin clouds of optical depths smaller than $\sim 0.3$ cover $\sim 50 \%$ of the globe (McFarquhar et al., 2000; Sun et al., 2011 b 2014) and play an important role in the radiation energy balance of the Earth (Dessler and Yang, 2003; Lee et al., 2009; Sun et al., 2011a, b), as well as in the remote sensing of aerosols (Sun et al., 2011b; Omar et al., 2013) and surface temperature (Sun et al., 2011a). Even a sky overhead that looks very clear and blue can still have "blue" clouds at over $34000 \mathrm{ft}$. altitude (Packer and Lock, 1951). These clouds are hard to be detected by space-borne instruments, thus complicate the retrieval of atmospheric constituents (Christi and Stephens, 2004). For example, the NASA Atmospheric $\mathrm{CO}_{2}$
Observations from Space (ACOS) XCO2 retrieval algorithm (O'Dell et al., 2012) defines clear-sky scenes for $\mathrm{CO}_{2}$ retrieval as cases with atmospheric optical depth $\leq 0.3$, which may still have super-thin cloud contamination. When undetected, super-thin clouds can introduce significant bias errors in the atmospheric carbon data measured by the ACOS and by the Orbiting Carbon Observatory 2 (OCO-2) mission (Crisp et al., 2004) due to the scattering of incident light by these clouds. This scattering introduces uncertainties in the optical path length and thus in the light absorption by $\mathrm{CO}_{2}$, from which the $\mathrm{CO}_{2}$ amount is retrieved. Unfortunately, the variation in surface background reflection means super-thin clouds generally cannot be detected by passive satellite instruments, like the OCO-2 (Crisp et al., 2004), the Moderate Resolution Imaging Spectroradiometer (MODIS) (King et al., 1992), and the Advanced Very High Resolution Radiometer (AVHRR) (Brest and Rossow, 1992), that only measure the total radiance of the reflected solar light (Minnis et al., 2002; Mace et al., 2005; Ackerman et al., 2008). Although many methods have been developed for detecting clouds (Gao and Kaufman, 1995; Wylie et al., 1995; Ackerman et al., 1998; Wylie and Menzel, 1999; Roskovensky and Liou, 2003), most super-thin clouds are still missing constituents of the atmosphere in satellite data. Lidars on NASA's Cloud-Aerosol Lidar and Infrared Pathfinder Satellite Observation (CALIPSO) (Winker et al., 2007) and Cloud-Aerosol Transport System (CATS) missions are the only instruments in orbit that can detect super-thin clouds; 
however, these only can cover small portions of the atmosphere. Long-term global surveys of super-thin clouds using space-borne lidars are limited by their large operational cost and narrow field of view. Also, noise in the lidar instantaneous measurements can be significant, due to its relatively low transmitted power, range length, narrow field of view, and contamination by sunlight. Although sunlight contamination is not an issue for lidar at nighttime, limited photons from narrow field of view received by lidar sensors still constitute errors for the detection of super-thin atmospheric constituents. To identify optically thin atmospheric components such as super-thin clouds, lidar data have to be averaged over a large spatial area to increase the number of photons measured and reduce the overall noise level. This spatial averaging could result in difficulties in using lidar data to study aerosol-cloud interactions in the neighborhood of clouds. The High Spectral Resolution Lidar (HSRL) technique (e.g. Rogers et al., 2011), which takes advantage of the spectral distribution of the lidar return to discriminate aerosol and molecular signals and thereby measure aerosol extinction and backscatter independently, would represent an advancement over the CALIPSO and the CATS measurements, but will also be limited in spatial coverage. Also, the signalto-noise levels associated with lidar measurements can limit the frequency with which super-thin clouds can be detected. Therefore, improving the space lidar systems and developing an inexpensive passive-remote-sensing method with greater spatial coverage for reliable detection of super-thin clouds have become critical issues for atmospheric remote-sensing practice.

In our previous work (Sun et al., 2014), we studied solar radiation backscattered from clouds with both the Polarization and Anisotropy of Reflectances for Atmospheric Science coupled with Observations from a Lidar (PARASOL) (Deschamps et al., 1994) data and an adding-doubling radiativetransfer model (ADRTM) (Sun and Lukashin, 2013). We found that the dominant backscattered electric field from the clear-sky Earth-atmosphere system is nearly parallel to the ocean surface. However, when clouds are present, this electric field can rotate significantly away from the parallel direction. We further discovered that this polarization feature can be used to detect super-thin cirrus clouds having an optical depth of only $\sim 0.06$ and super-thin liquid water clouds having an optical depth of only $\sim 0.01$. Such clouds are too thin to be sensed using any current passive satellite instruments.

In this study, we further develop this algorithm not only to find super-thin clouds, but also to retrieve their optical depth (OD) quantitatively. Note that this algorithm is developed as a means to remotely sense clouds that cannot be detected by other passive remote-sensing techniques, to help the remote sensing of optically thin atmospheric constituents and sea surface temperature that require clear-sky conditions. Any cases that include thick clouds which can be observed by conventional ways are outside of the scope of this study. In Sect. 2, modeling results supplementary to the work in Sun et al. (2014) are reported for the polarization feature of reflected sunlight from clouds. The algorithm for retrieving the OD of super-thin clouds with polarized sunlight is introduced in Sect. 3. We make concluding remarks in Sect. 4.

\section{$2 \quad \boldsymbol{P}$-polarization feature of reflected sunlight from clouds}

As a complement to the work in Sun et al. (2014), we further modeled the angle of linear polarization (AOLP) of reflected sunlight from clouds of different thermodynamic phases, particle shapes, and optical depth over oceans. In the modeling, the atmosphere, including the cloud and aerosol layers, is assumed to be plane-parallel. The cloud is assumed to be a homogeneous single layer over ocean surface. The atmospheric profiles are from the US Standard Atmosphere (National Oceanic and Atmospheric Administration, National Aeronautics and Space Administration, and United States Air Force, 1976). The $p$-polarization feature of the reflected sunlight from clouds is our focus in this study. Note that here, " $p$-polarization" means that the polarized electric field is parallel to the meridian plane of the reflected light, as shown in Fig. 1 of Sun and Lukashin (2013), and it is $\sim 0^{\circ} / 180^{\circ}$ in terms of the AOLP in this work.

Figure 1 shows the modeled AOLP of reflected sunlight as a function of viewing zenith angle (VZA) and relative azimuth angle (RAZ) at a wavelength of $670 \mathrm{~nm}$ from water clouds with different optical depth (OD) over ocean. In the ADRTM modeling, the ocean wind speed is assumed to be $7.5 \mathrm{~m} \mathrm{~s}^{-1}$, the solar zenith angle (SZA) is $29.17^{\circ}$, and the aerosol optical depth (AOD) is 0.06. The modified gamma (MG) particle size distribution (PSD) is assumed for water cloud droplets

$\mathrm{d} N / \mathrm{d} R=N_{0} R^{v} \exp \left(-v \frac{R}{R_{0}}\right)$,

where $R$ denotes the droplet radius, $R_{0}$ is the modal radius, $v$ defines the shape of the distribution, and

$N_{0}=\frac{v^{v+1}}{\Gamma(v+1) R_{0}^{v+1}} N_{\text {tot }}$

is a constant, with $\Gamma(v+1)$ as the gamma function and $N_{\text {tot }}$ as the total number of particles per unit volume (Petty and Huang, 2011). The commonly used $\mathrm{C} 1$ size distribution (Deirmendjian, 1969), which is defined by Eq. (1) with $R_{0}=4 \mu \mathrm{m}$ and $\nu=6$, is applied in this study. The water cloud is within an altitude range of $2-3 \mathrm{~km}$. We can see that the near-backscatter $p$-polarization feature of the reflected light is evident, even when the cloud OD is as small as 0.01 . With the increase of the cloud OD, this pattern becomes stronger, and when cloud OD $>\sim 0.5$, it becomes saturated. Therefore, using the near-backscatter $p$-polarization feature of the reflected light, we can detect any water clouds, including subvisible ones with $\mathrm{OD}<0.03$, over oceans. 

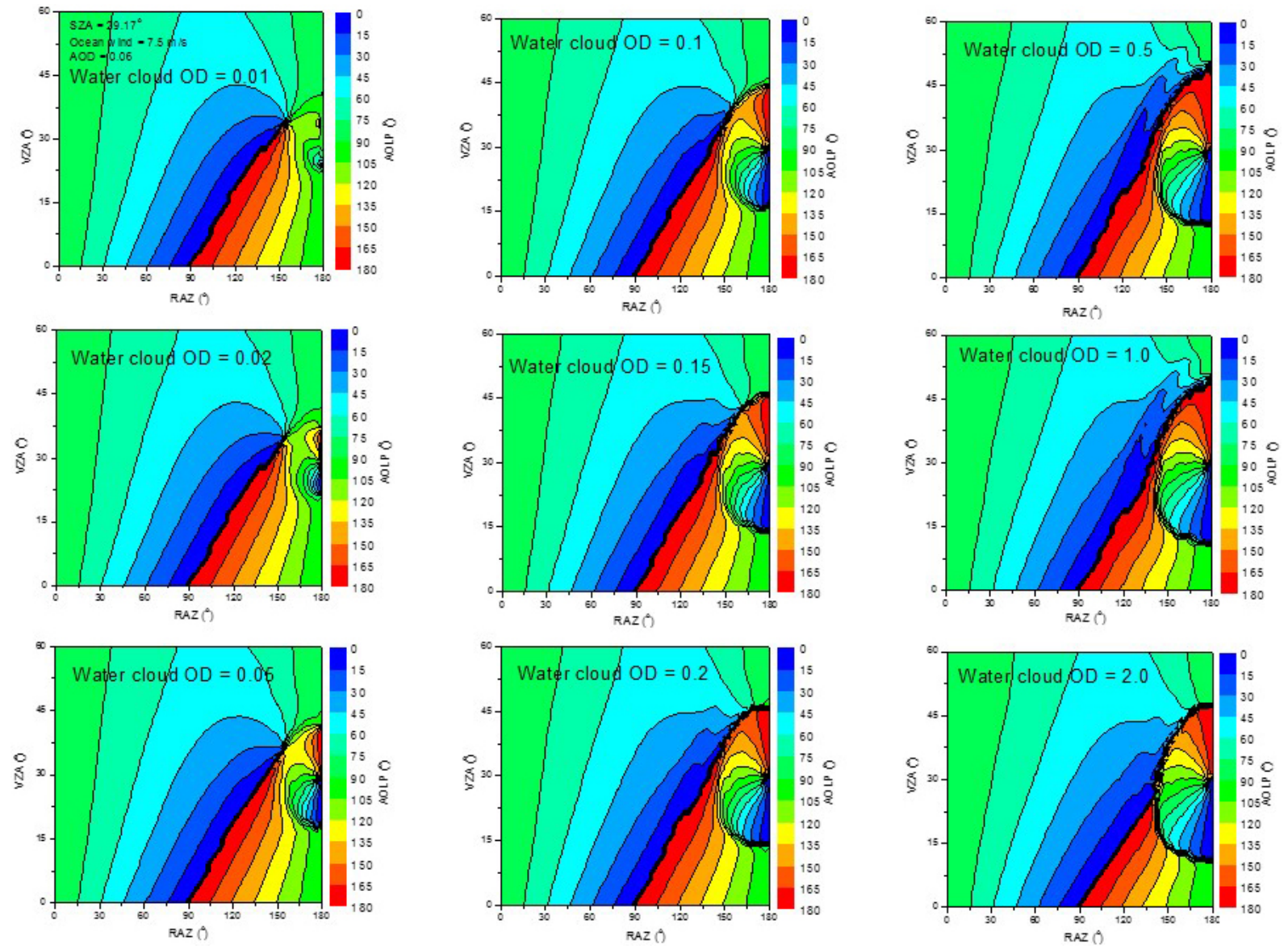

Figure 1. The angle of linear polarization (AOLP) of reflected sunlight at $670 \mathrm{~nm}$ from water clouds showing that even clouds with optical depths (OD) of 0.01 exhibit the near-backscatter $p$-polarization feature. In the ADRTM modeling, the clouds' ODs are set from 0.01 to 2.0, the ocean wind speed is assumed to be $7.5 \mathrm{~m} \mathrm{~s}^{-1}$, the solar zenith angle (SZA) is $29.17^{\circ}$, and the aerosol optical depth (AOD) is 0.06 . The C1 size distribution (Deirmendjian, 1969) is used for water cloud droplets.

Figure 2 shows the modeled AOLP of reflected sunlight as a function of VZA and RAZ at a wavelength of $670 \mathrm{~nm}$ from cirrus clouds. In the ADRTM modeling, the clouds' ODs are set from 0.01 to 2.0, the ocean wind speed is assumed to be $7.5 \mathrm{~m} \mathrm{~s}^{-1}$, the SZA is $29.17^{\circ}$, and the AOD is 0.06 . The cirrus cloud is within an altitude range of $7-8 \mathrm{~km}$. The size distribution of the ice particles in the cirrus clouds is from Heymsfield and Platt (1984) for the cloud temperature of -20 to $-25^{\circ} \mathrm{C}$. The cirrus clouds are assumed to be composed of solid hexagonal column ice crystals with aspect ratios as given in Fu et al. (1998). The calculation of the single-scattering properties of the ice crystals is described in Baum et al. (2000). We can see that similar to water clouds, cirrus clouds composed of hexagonal column ice crystals reflect sunlight with a significant near-backscatter $p$ polarization feature, even when their OD is only $\sim 0.01$. This means that if ice cloud particle shapes are not complex, the clouds can be detected by the near-backscatter $p$-polarization feature even if it is invisible with respect to standard passive remote-sensing techniques. It is known that super-thin cirrus clouds more often appear in the tropical tropopause layer from 14.5 to $18.5 \mathrm{~km}$ (Fu et al., 2007; Virts et al., 2010), where the shapes of ice particles are more regular hexagonal columns, since they form in situ due to the large-scale slow uplift. Our results in Fig. 2 show that these clouds could be well detected by the near-backscatter $p$-polarization feature of the reflected light. However, when cloud particle shapes are complex, such as a mixture of irregular particle shapes for tropical cirrus clouds as described in Meyer et al. (2004), Fig. 3 demonstrates that the near-backscatter $p$-polarization feature can hardly be seen for cloud ODs $<\sim 0.02$. Despite this limitation, the approach should be able to reliably detect ice clouds with a mixture of complex particle shapes when their OD $>\sim 0.06$ (Sun et al., 2014).

We briefly explained the background physics of the nearbackscatter $p$-polarization feature of reflected sunlight from clouds in Sun et al. (2014). To further explain the physics behind the optical phenomenon, we refer to well-known aspects of reflection theory in geometric optics as illustrated in Fig. 4. When natural light interacts with a water surface, 

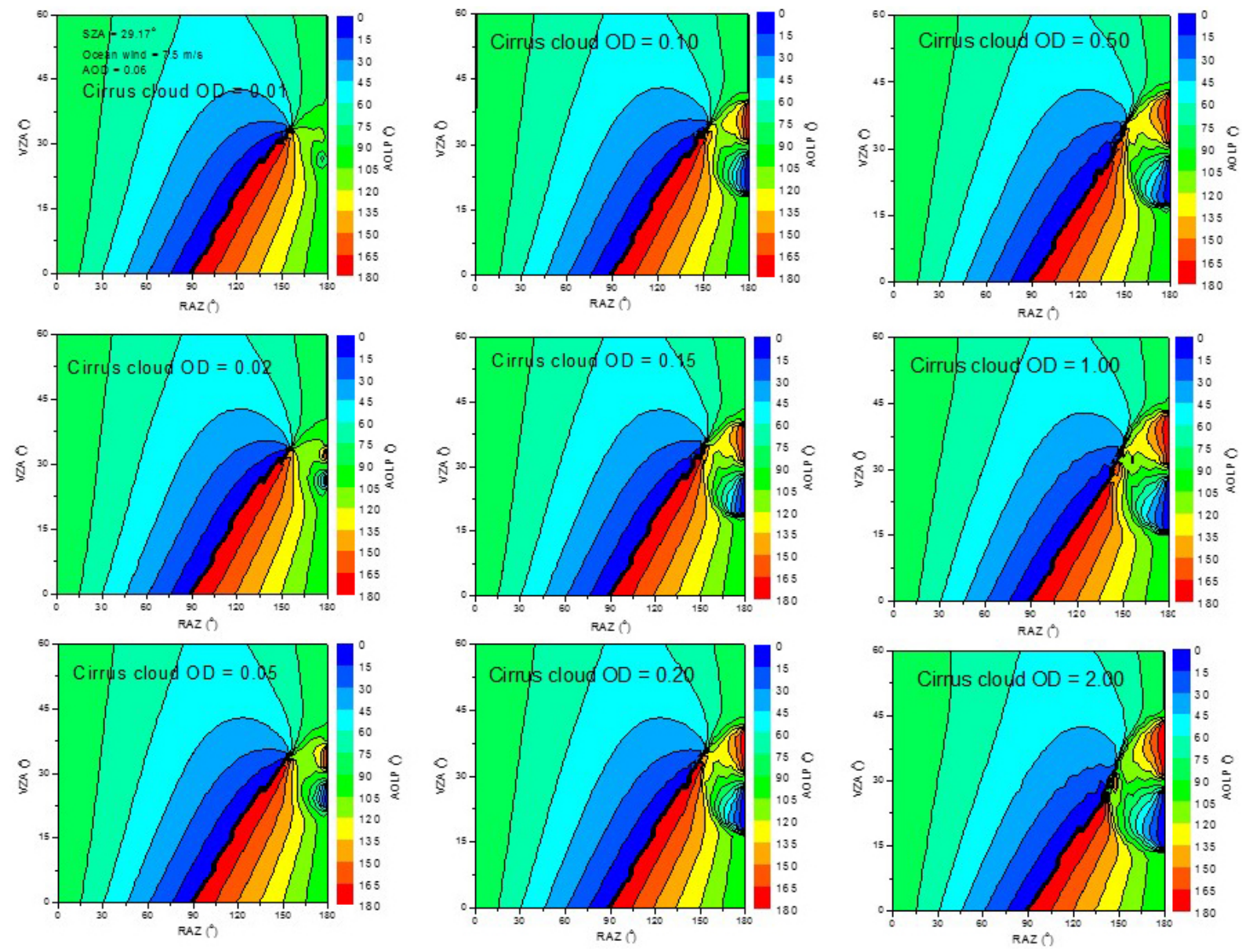

Figure 2. The modeled AOLP of reflected sunlight at a wavelength of $670 \mathrm{~nm}$ from cirrus clouds (hexagonal column particle shapes). In the ADRTM modeling, the clouds' optical depths (OD) are set from 0.01 to 2.0 , the ocean wind speed is assumed to be $7.5 \mathrm{~m} \mathrm{~s}{ }^{-1}$, the solar zenith angle (SZA) is $29.17^{\circ}$, and the aerosol optical depth (AOD) is 0.06 . The size distribution of the ice particles in the cirrus clouds is from Heymsfield and Platt (1984) for the cloud temperature of -20 to $-25^{\circ} \mathrm{C}$. The cirrus clouds are assumed to be composed of solid hexagonal column ice crystals with aspect ratios as given in Fu et al. (1998). Similar to water clouds, cirrus clouds composed of hexagonal column ice crystals exhibit the $p$-polarization feature, even when their OD is $\sim 0.01$

the reflected field tends to be polarized parallel to the surface ( $s$-polarized) and the transmitted field tends to be polarized within the plane of incidence ( $p$-polarized). This also occurs in ray-tracing from large water droplets, where the internal fields have a tendency to favor the $p$-polarization state. One manifestation of this can be seen in the glory, which occurs at near-backscattered angles and is $p$-polarized. If the particle strongly absorbs light, like some aerosols, the refracted light cannot emerge from the particle, and the $p$-polarization feature is not observed. In addition, if the particle shape/surface is complex, like ice particle aggregates, the refracted light has weaker constructive interference, resulting in a weaker $p$-polarization feature. As the particle size becomes small, like stratospheric liquid sulfur aerosols, the little phase differences occur between paths within the particle, scattering features become broader, and the glory feature disappears. Furthermore, if the background surface can be characterized by single-scattering facets, like a water surface, the dominant reflected electric field from the surface at the near-backscatter direction is parallel to the surface (i.e., $s$-polarized to the meridian plane of reflected light) (Sun et al., 2014), thus the $p$-polarization feature of the reflected light unambiguously indicates the presence of clouds. However, if the ground surface is not single-scattering-dominated, such as needle-leaf trees and grasslands, the electric field of reflected sunlight directly from the surface may not always be parallel to the surface, where the $p$-polarized light from the multiple-scattering surface introduces uncertainties in the method. Under this condition, the OD must be large for the cloud to be identified unambiguously. For example, our modeling shows that over the desert, the OD should be larger than $\sim 0.1$ for a cloud to be detected by this method. This highlights some limitations of using reflected light's $p$-polarization feature to detect particulates in the atmosphere. 

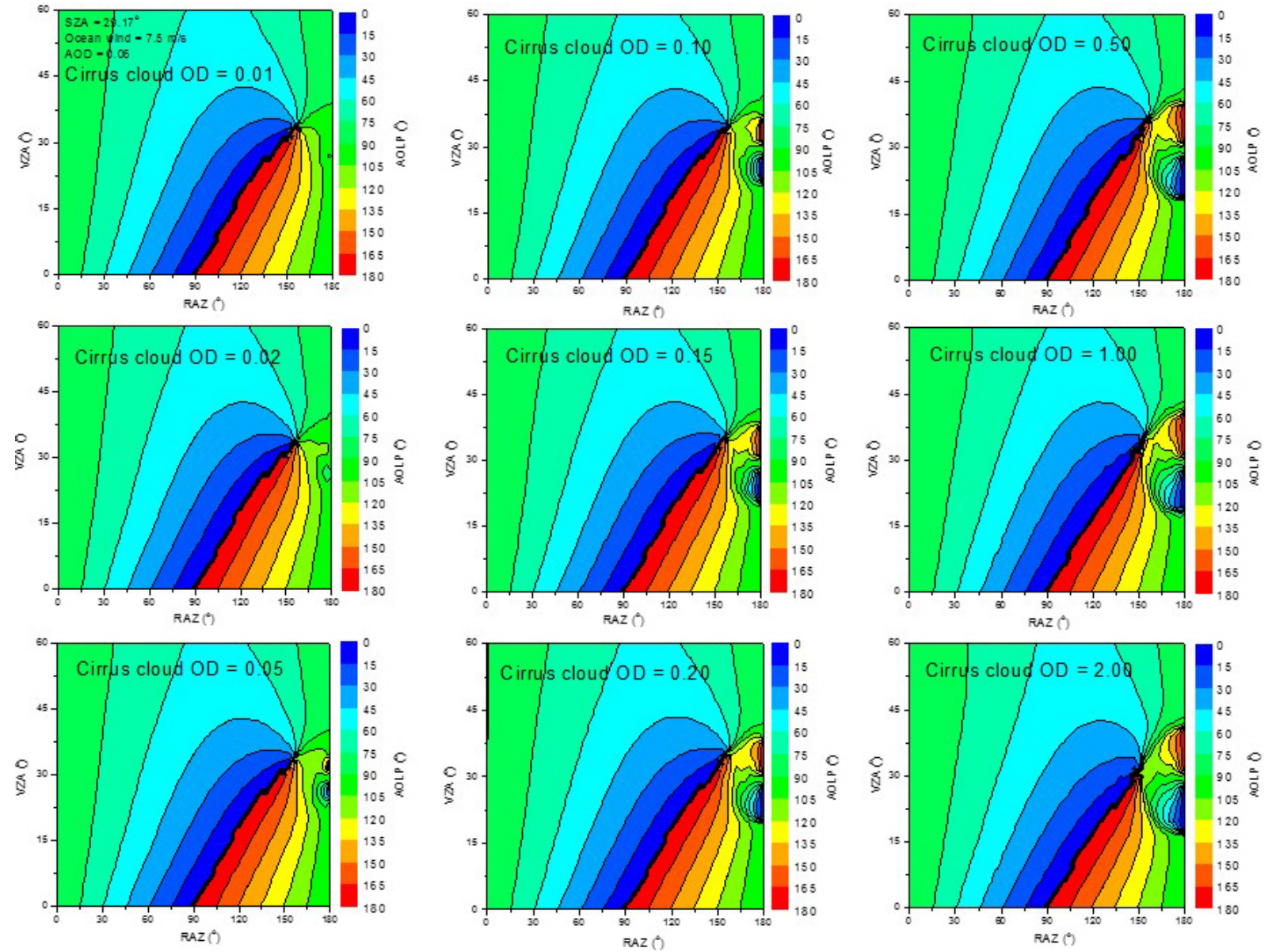

Figure 3. The modeled AOLP of reflected sunlight at a wavelength of $670 \mathrm{~nm}$ from cirrus clouds (complex particle shapes). In the ADRTM modeling, the clouds' optical depths (OD) are set from 0.01 to 2.0 , the ocean wind speed is assumed to be $7.5 \mathrm{~m} \mathrm{~s}^{-1}$, the solar zenith angle (SZA) is $29.17^{\circ}$, and the aerosol optical depth (AOD) is 0.06 . The size distribution of the ice particles in the cirrus clouds is from Heymsfield and Platt (1984) for the cloud temperature of -20 to $-25^{\circ} \mathrm{C}$. The cirrus clouds are assumed to be composed of a mixture of complex particle shapes for tropical cirrus clouds as described in Meyer et al. (2004). Cirrus clouds composed of complex particle shapes crystals exhibit the $p$-polarization feature when their OD is $>0.06$.

The results reported in Sun et al. (2014) and in this section clearly demonstrate that super-thin clouds can be reliably detected by the $p$-polarization feature of reflected sunlight from them. However, because the AOLP of reflected light (which can be derived from the ratio of polarized intensities $Q$ and $U$ ) is not very sensitive to cloud optical depth, we must develop a new algorithm for the quantitative retrieval of superthin cloud optical depth.

\section{Method for retrieving super-thin cloud optical depth}

Because of variations in surface reflections and atmospheric profiles, using total reflected intensity to detect superthin clouds is generally difficult. Remote sensing atmospheric particulates using polarization measurements in the backscattering region can minimize surface, molecule, and absorbing gas interferences, thus increasing the sensitivity to

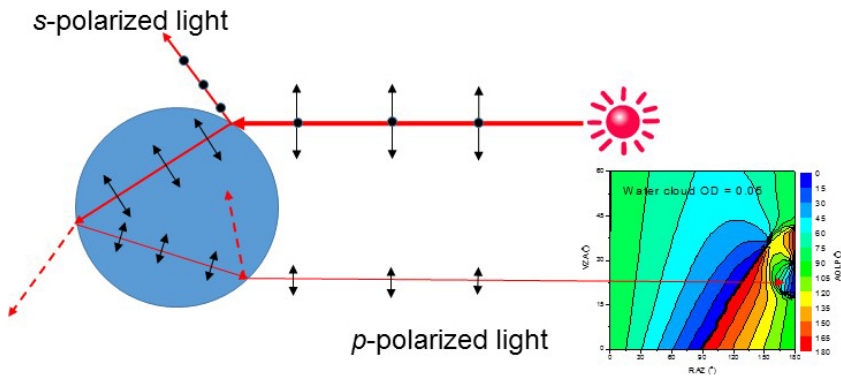

Figure 4. Illustration of the physics for the near-backscatter $p$ polarization feature of the reflected light from clouds.

atmospheric particulates, like super-thin clouds (Sun et al., 2014). With super-thin cirrus clouds as an example, the difference between Fig. 5a and b from our previous work (Sun et al., 2014) demonstrates that at viewing angles in the neigh- 
borhood of the backscattering direction, the clear-sky AOLP of reflected sunlight at a wavelength of $\lambda=670 \mathrm{~nm}$ can be used to locate super-thin clouds. In this study, we further find that the optical depth of super-thin clouds can be retrieved at viewing angles in the neighborhood of the backscattering direction. Following the previous discussion (Sun et al., 2014), we refer to these regions as the "glory angles" that are within $\pm \sim 8^{\circ}$ around the backscattering direction and include the blue and yellow spots in Fig. 5b. To exclude the effect of background reflection, we will use only the polarized component of the backscattered light parallel to the meridian plane of the reflected light ( $p$-polarized light) for the OD retrieval. Since the clear-sky surface background reflection is only perpendicular to the meridian plane of the reflected light ( $s$-polarized) in the neighborhood of the backscattering direction (Fig. 5a), the $p$-polarized component of the backscattered light is caused by super-thin clouds (Sun et al., 2014). Assuming that the linearly polarized electric field of the reflected light from the Earth-atmosphere system is $E_{p}$, we can express its $p$-polarized component as (See Fig. 1 in Sun and Lukashin, 2013)

$E_{p}^{\perp}=E_{p} \cos (\mathrm{AOLP})$

Therefore, the $p$-polarized reflectance is in the form

$I_{p}^{\perp}=I_{p} \cos ^{2}(\mathrm{AOLP})$

where $I_{p}=\sqrt{Q^{2}+U^{2}}$ denotes the polarized reflectance. For a clear-sky system in which the AOLP $\sim 90^{\circ}$ at our specific observation direction, $\left[I_{p} \cos ^{2}(\right.$ AOLP $\left.)\right] \sim 0$. In a system containing super-thin clouds or heavy aerosols in which the AOLP $\sim 0^{\circ} / 180^{\circ}$ in the observation direction, $\left[I_{p} \cos ^{2}(\mathrm{AOLP})\right] \sim I_{p}$. At this specific observation direction, the OD can be retrieved from the polarized reflectance and the AOLP as

$\mathrm{OD}=f^{-1}\left[I_{p} \cos ^{2}(\mathrm{AOLP})\right]$

where $f^{-1}[]$ denotes a function that will be determined by the OD and $\left[I_{p} \cos ^{2}\right.$ (AOLP) $]$ correlation curve from modeling results for various super-thin clouds.

Figure 6 shows the modeled $p$-polarized reflectance at a wavelength of $670 \mathrm{~nm}$ as a function of VZA and at a RAZ of $177^{\circ}$ for a clear and super-thin cloud scene over oceans with different wind speeds. In the modeling, the SZA is $29.17^{\circ}$ and the AOD is 0.1. The size distribution of the ice particles in the cirrus clouds is from Heymsfield and Platt (1984) for the cloud temperature of -20 to $-25^{\circ} \mathrm{C}$. The cirrus cloud is assumed to be composed of hexagonal ice columns and is contained within an altitude range of $7-8 \mathrm{~km}$. Results for clear oceans (dotted curves) and oceans with a cirrus layer with an OD of 0.1 (solid curves) are shown. Different colors represent different wind speeds: $2.5 \mathrm{~m} \mathrm{~s}^{-1}$ (black), $7.5 \mathrm{~m} \mathrm{~s}^{-1}$ (red), and $12.5 \mathrm{~m} \mathrm{~s}^{-1}$ (blue). We can see that for
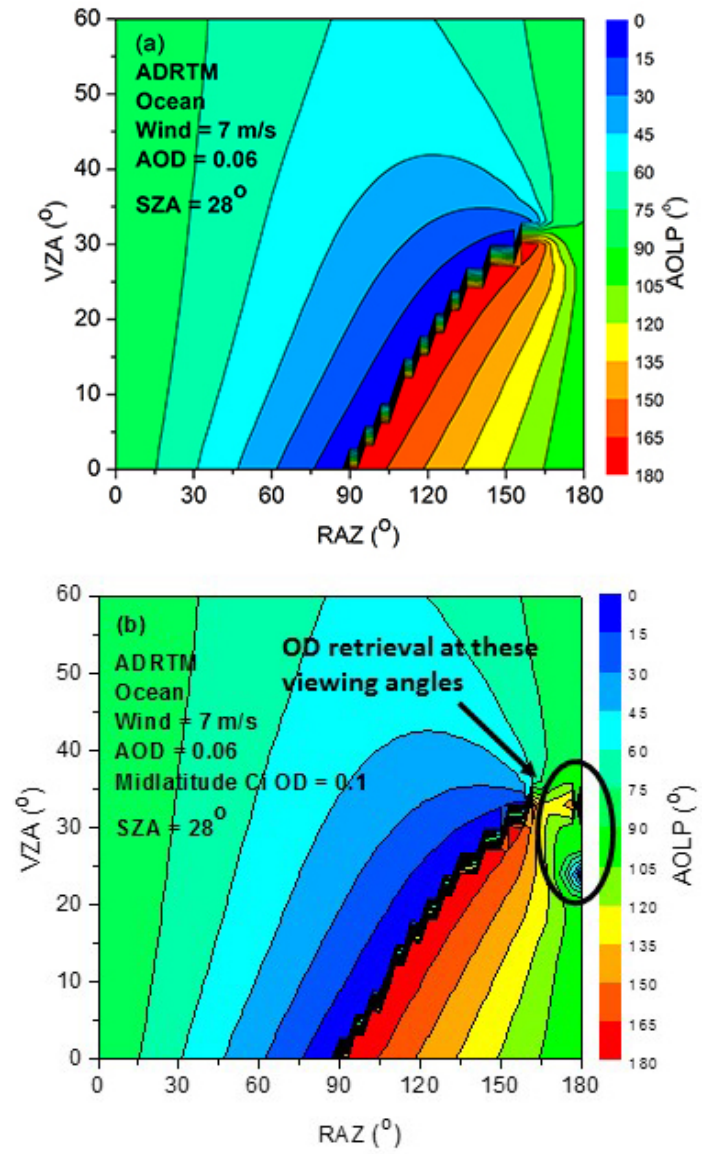

Figure 5. The modeled AOLP at a wavelength of $670 \mathrm{~nm}$ as a function of viewing zenith angle (VZA) and relative azimuth angle (RAZ) from (a) the ADRTM for clear-sky oceans and (b) the ADRTM for oceans with a layer of super-thin clouds. In the modeling, the solar zenith angle (SZA) is $28^{\circ}$, ocean wind speed is $7 \mathrm{~m} \mathrm{~s}^{-1}$, the sea-salt aerosol optical depth (AOD) is 0.06 , and a layer of mid-latitude cirrus cloud with an optical depth of 0.1 is assumed with an altitude range of $7-8 \mathrm{~km}$. The difference of Fig. 5a and $b$ shows the effect of super-thin clouds on the reflected sunlight's AOLP. This figure is reproduced from Sun et al. (2014).

clear-sky oceans, $\left[I_{p} \cos ^{2}(\mathrm{AOLP})\right]$ varies with the ocean surface roughness (wind speed) and its magnitude is low. However, when there is a layer of thin cloud over the oceans, at the glory angles, $\left[I_{p} \cos ^{2}(\mathrm{AOLP})\right]$ is about 1 order of magnitude larger than the clear-sky values and has a very small dependence on the ocean surface conditions. This is very important, since surface conditions can vary widely, and a significant dependence would complicate the OD retrievals. Figure 6 demonstrates that $\left[I_{p} \cos ^{2}(\mathrm{AOLP})\right]$ is a robust quantity that can be used to retrieve the OD of optically thin clouds regardless of ocean surface conditions.

Figure 7 shows the modeled $p$-polarized reflectance at a wavelength of $670 \mathrm{~nm}$ as a function of VZA and at a RAZ of $177^{\circ}$ for super-thin cirrus clouds over oceans with different ODs (solid curves). Also shown in the figure is the result for 


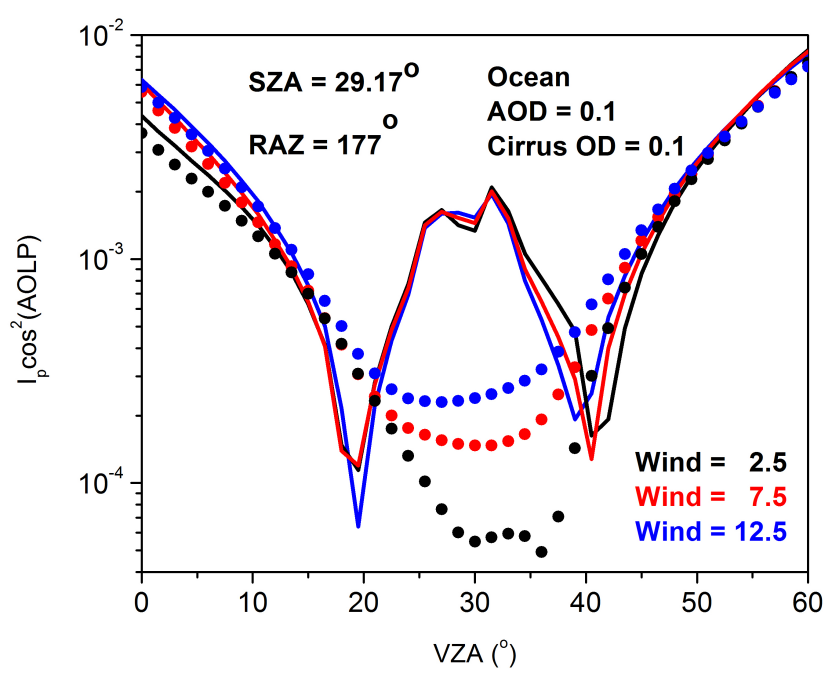

Figure 6. Modeled p-polarized reflectance at a wavelength of $670 \mathrm{~nm}$ as a function of viewing zenith angle (VZA), and at a relative azimuth angle (RAZ) of $177^{\circ}$ for clear and super-thin clouds over oceans with different wind speeds. In the modeling, the solar zenith angle (SZA) is $29.17^{\circ}$, and the aerosol optical depth (AOD) is 0.1 . Results for clear oceans (dots) and oceans with a cirrus layer with an optical depth (OD) of 0.1 (solid curves) are shown. The size distribution of the ice particles in the cirrus clouds is from Heymsfield and Platt (1984) for the cloud temperature of -20 to $-25^{\circ} \mathrm{C}$. The cirrus clouds are assumed to be composed of hexagonal ice columns with aspect ratios as given in Fu et al. (1998).

clear oceans (black dots). In the modeling, the SZA is $29.17^{\circ}$, the wind speed is $7.5 \mathrm{~m} \mathrm{~s}^{-1}$, and the aerosol optical depth (AOD) is 0.1. The size distribution of the ice particles in the cirrus clouds is from Heymsfield and Platt (1984) for the cloud temperature of -20 to $-25^{\circ} \mathrm{C}$. The mid-latitude cirrus cloud is assumed to be composed of a mixture of complex particle shapes as described in Baum et al. (2000) and to be within an altitude range of $7-8 \mathrm{~km}$. We can see that with the increase of cloud OD, $\left[I_{p} \cos ^{2}\right.$ (AOLP) $]$ systematically increases at the glory angle region. When cloud OD approaches $\sim 0.6,\left[I_{p} \cos ^{2}\right.$ (AOLP) $]$ becomes saturated and it is difficult to differentiate the OD of the respective clouds. Therefore, this OD retrieval method may only work well for thin clouds that have OD $<\sim 0.6$. From the same calculations of Fig. 7, the modeled $p$-polarized reflectance at $670 \mathrm{~nm}$ as a function of cloud optical depth (OD) at a VZA of $28.5^{\circ}$ and a RAZ of $177^{\circ}$ for super-thin cirrus clouds over oceans is displayed in Fig. 8. We can see that $\left[I_{p} \cos ^{2}\right.$ (AOLP) $]$ is nearly linearly related to cloud OD when the cloud OD $<\sim 0.6$. Therefore, based on this type of relationship, super-thin cloud OD can be retrieved from the $\left[I_{p} \cos ^{2}\right.$ (AOLP)]. The OD and $\left[I_{p} \cos ^{2}\right.$ (AOLP)] correlation curve in Fig. 8 is just an example of the $f^{-1}[]$ in Eq. (5).

Since this algorithm uses near-backscatter polarized reflectance for retrieval of cloud optical depth, obviously it is sensitive to cloud thermodynamic phase or particle size

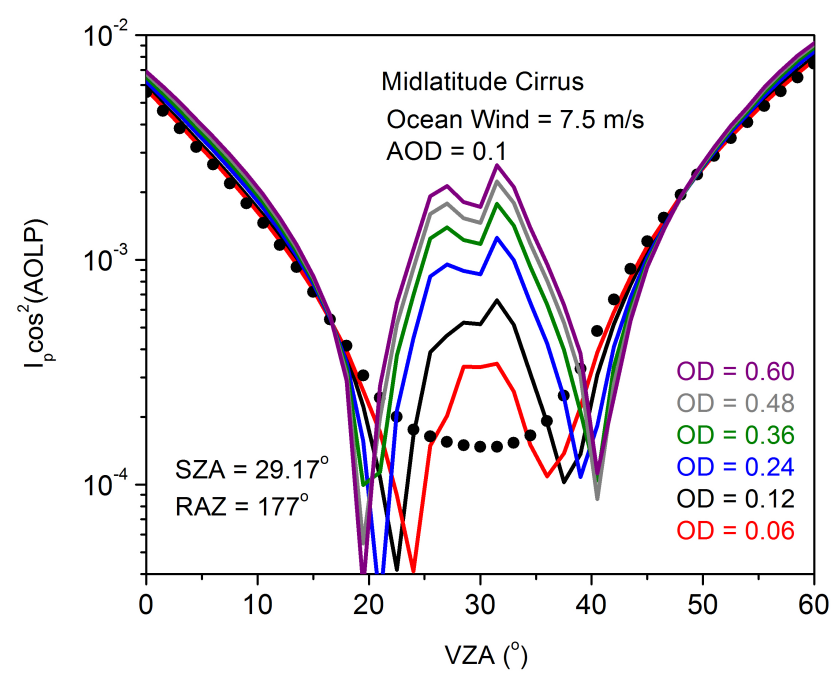

Figure 7. Modeled p-polarized reflectance at a wavelength of $670 \mathrm{~nm}$ as a function of viewing zenith angle (VZA), and at a relative azimuth angle (RAZ) of $177^{\circ}$ for super-thin cirrus clouds over oceans with different optical depth (OD) (solid curves). Also shown in the figure is the result for clear oceans (black dots). In the modeling, the solar zenith angle (SZA) is $29.17^{\circ}$, the wind speed is $7.5 \mathrm{~m} \mathrm{~s}^{-1}$, and the aerosol optical depth (AOD) is 0.1 . The size distribution of the ice particles in the cirrus clouds is from Heymsfield and Platt (1984) for the cloud temperature of -20 to $-25^{\circ} \mathrm{C}$. The mid-latitude cirrus clouds are composed of a mixture of complex particle shapes as described in Baum et al. (2000). These results suggest that the OD retrieval method may only work well for thin clouds which have $\mathrm{OD}<\sim 0.6$.

and shape if the cloud is cirrus or mixed-phase. Thus, $\left[I_{p} \cos ^{2}\right.$ (AOLP)] must be some function of ice cloud particle size and shape, or liquid water cloud size distribution. Reliably detecting the thermodynamic phase of the clouds is a prerequisite for a good retrieval using this method. Using the oxygen A-band (759-770 nm) (Min et al., 2014) $\left[I_{p} \cos ^{2}(\mathrm{AOLP})\right]$ to estimate the altitude of the clouds could help to determine the cloud thermodynamic phase. On the other hand, a detailed study of the effects of particle size and shape of the clouds on the polarized reflectance from them is also necessary in the application of this method. As an example, Fig. 9 shows the modeled $p$-polarized reflectance at a wavelength of $670 \mathrm{~nm}$ as a function of VZA and at a RAZ of $177^{\circ}$ for super-thin cirrus clouds over oceans with different ODs. In the modeling, the SZA is $29.17^{\circ}$, the wind speed is $7.5 \mathrm{~m} \mathrm{~s}^{-1}$, and the AOD is 0.06 . The size distribution of the ice particles in the cirrus clouds is from Heymsfield and Platt (1984) for the cloud temperature of -20 to $-25^{\circ} \mathrm{C}$. The cirrus clouds are assumed to be within an altitude range of $7-$ $8 \mathrm{~km}$ and composed of mixtures of complex particle shapes for typical mid-latitude cirrus clouds as described in Baum et al. (2000) (open circles) and tropical cirrus clouds as described in Meyer et al. (2004) (solid curves). It can be seen that different mixtures of ice cloud particle shapes can result 


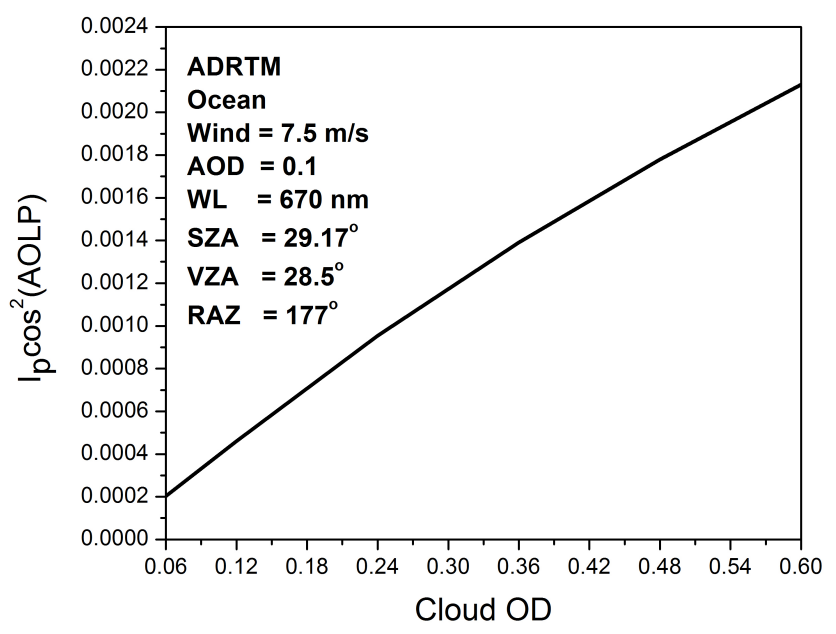

Figure 8. Modeled p-polarized reflectance at a wavelength of 670 $\mathrm{nm}$ as a function of cloud optical depth (OD), at a viewing zenith angle (VZA) of $28.5^{\circ}$, and a relative azimuth angle (RAZ) of $177^{\circ}$ for super-thin cirrus clouds over oceans. The solar zenith angle (SZA) is $29.17^{\circ}$, the wind speed is $7.5 \mathrm{~m} \mathrm{~s}^{-1}$, and the aerosol optical depth (AOD) is 0.1 . The size distribution of the ice particles in the cirrus clouds is from Heymsfield and Platt (1984) for the cloud temperature of -20 to $-25^{\circ} \mathrm{C}$. The mid-latitude cirrus clouds are composed of a mixture of complex particle shapes as described in Baum et al. (2000). This figure shows the nearly linearly relationship between cloud OD and AOLP for OD $<0.6$.

in different $\left[I_{p} \cos ^{2}(\mathrm{AOLP})\right]$. This can cause an uncertainty of $\sim 0.05$ in the retrieved cloud OD.

It is worth noting here that in Figs. 6, 7, and 9, for each case of the $p$-polarized reflectance curves of clouds, at the boundary of the glory angle region, $\left[I_{p} \cos ^{2}(\mathrm{AOLP})\right]$ drastically dips to a very small value and our angular discretization in the modeling sometimes misses the capture of the lowest point. A plausible explanation for this phenomenon is that it is the transitional region between backscattered $p$ polarized rays from the particles and the $s$-polarized rays from the surface, where surface background $s$-polarized reflectance cancels $p$-polarized reflectance from clouds; thus $p$-polarized light is nearly zero and AOLP is close to $90^{\circ}$, so $I_{p} \cos ^{2}$ (AOLP) can be very small.

\section{Conclusion}

In summary, our previous studies with the PARASOL satellite data and the ADRTM results in Sun et al. (2014) and in this work show that the AOLP of scattered sunlight observed in two distinct angular glory regions near the exactbackscatter direction can be used to detect water clouds with an OD of only $\sim 0.01$ and ice clouds with an OD of only $\sim 0.06$. In this paper, we show that the $p$-polarized reflectance $\left[I_{p} \cos ^{2}(\mathrm{AOLP})\right]$ at near-backscatter-viewing angles can be used for the retrieval of the optical depth of superthin clouds, with little effect from ocean surface conditions.

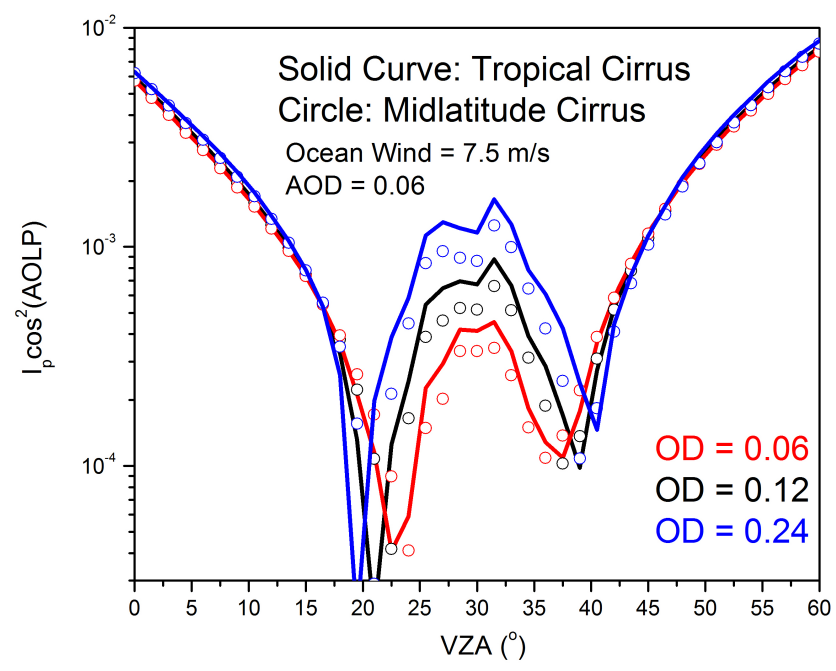

Figure 9. Modeled p-polarized reflectance at a wavelength of $670 \mathrm{~nm}$ as a function of viewing zenith angle (VZA), and at a relative azimuth angle (RAZ) of $177^{\circ}$ for super-thin cirrus clouds over oceans with different optical depth (OD). In the modeling, the solar zenith angle (SZA) is $29.17^{\circ}$, the wind speed is $7.5 \mathrm{~m} \mathrm{~s}^{-1}$, and the aerosol optical depth (AOD) is 0.06 . The size distribution of the ice particles in the cirrus clouds is from Heymsfield and Platt (1984) for the cloud temperature of -20 to $-25^{\circ} \mathrm{C}$. The clouds are composed of mixtures of complex particle shapes for typical mid-latitude cirrus clouds as described in Baum et al. (2000) (open circles) and tropical cirrus clouds as described in Meyer et al. (2004) (solid curves). This illustrates that with inadequate knowledge of cloud particle shapes, uncertainties of up to $\sim 0.05$ in the retrieved cloud OD can be obtained.

Our sensitivity study shows that for a polarization intensity, measurements with $\sim 10 \%$ calibration error, such as those from the PARASOL $670 \mathrm{~nm}$ channel (Fougnie et al., 2007), this algorithm can have $\sim 0.006$ uncertainty in the retrieved super-thin cloud OD. This is a robust algorithm, which could be used to conduct inexpensive surveys for super-thin clouds over mid-latitude and tropical areas, where most super-thin clouds exist (Sun et al., 2011b).

However, as an algorithm based on a low-cost passive instrument measuring reflected solar light, it has difficulties in detecting super-thin clouds over thick clouds, since the thick clouds' glory pattern is much stronger than that of super-thin clouds. For these multilayer cases, this method can only detect that there are thick clouds present. Moreover, since the glory pattern is a special optical phenomenon of transparent cloud droplets or ice crystals, this algorithm is not sensitive to background aerosols that coexist with super-thin clouds. However, heavy aerosols (OD>0.2) can cause an electric field on the principal plane not parallel to the ocean surface, at viewing zenith angles smaller than the backscattering angle, which will result in some ambiguities for retrieval; however, they cannot produce the full glory pattern as shown in Figs. 1-3, i.e. electric fields in all radial directions around the 
backscattering direction. Also, as a method based on measurements of reflected sunlight, this algorithm obviously cannot work at night. However, it is important to note that our studies suggest, based on Raman lidar data, that super-thin clouds differ little between day and night, because of their insignificant absorption to solar radiation. Active instruments such as space-borne lidars can work during both day and night and can measure cloud/aerosol altitude, but their swath width is narrow though they produce profiles along the satellite track. In addition, the limited number of photons acquired from space-borne lidars reduces the signal-to-noise level and can introduce errors in their measured data. Thus, both passive and active instrument techniques have their advantages and disadvantages; exploring innovative algorithms to make greater use of existing passive remote-sensing instruments and to complement active remote-sensing instruments is an obvious benefit. The insights gained from identifying superthin clouds can have a significant impact on surface and atmospheric constituents remote sensing and shed greater light on the role clouds play in the larger Earth-atmosphere system.

Acknowledgements. This work was supported by NASA Glory fund 09-GLORY09-0027. The authors thank Michael I. Mishchenko and Hal B. Maring for this support. Wenbo Sun also thanks Bruce A. Wielicki for helpful discussions and the support from NASA CLARREO mission for this work.

Edited by: J. Huang

\section{References}

Ackerman, S. A., Strabala, K. I., Menzel, W. P., Frey, R. A., Moeller, C. C., and Gumley, L. E.: Discriminating clear sky from clouds with MODIS, J. Geophys. Res., 103, 32141-32157, doi:10.1029/1998JD200032, 1998.

Ackerman, S. A., Holz, R. E., Frey, R., Eloranta, E. W., Maddux, B. C., and McGill, M.: Cloud detection with MODIS. Part II: Validation, J. Atmos. Ocean. Tech., 25, 1073-1086, doi:10.1175/2007JTECHA1053.1, 2008.

Baum, B. A., Kratz, D. P., Yang, P., Ou, S. C., Hu, Y., Soulen, P. F., and Tsay, S. C.: Remote sensing of cloud properties using MODIS airborne simulator imagery during SUCCESS. I. Data and models, J. Geophys. Res., 105, 11767-11780, 2000.

Brest, C. L. and Rossow, W. B.: Radiometric calibration and monitoring of NOAA AVHRR data for ISCCP, Int. J. Remote Sens., 13, 235-273, 1992.

Christi, M. J. and Stephens, G. L.: Retrieving profiles of atmospheric $\mathrm{CO} 2$ in clear sky and in the presence of thin cloud using spectroscopy from the near and thermal infrared: A preliminary case study, J. Geophys. Res., 109, D04316, doi:10.1029/2003JD004058, 2004.

Crisp, D., Atlas, R. M., Breon, F.-M., Brown, L. R., Burrows, J. P., Ciais, P., Connor, B. J., Doney, S. C., Fung, I. Y., Jacob, D. J., Miller, C. E., O’Brien, D., Pawson, S., Randerson, J. T., Rayner,
P., Salawitch, R. J., Sander, S. P., Sen, B., Stephens, G. L., Tans, P. P., Toon, G. C., Wennberg, P. O., Wofsy, S. C., Yung, Y. L., Kuang, Z., Chudasama, B., Sprague, G., Weiss, B., Pollock, R., Kenyon, D., and Schroll, S.: The orbiting carbon observatory (OCO) mission, Adv. Space Res., 34, 700-709, 2004.

Deirmendjian, D.: Electromagnetic scattering on spherical polydispersions, American Elsevier Publishing Company, Inc., New York, 1969.

Deschamps, P. Y., Breon, F.-M., Leroy, M., Podaire, A., Bricaud, A., Buriez, J.-C., and Seze, G.: The POLDER mission: Instrument characteristics and scientific objectives, IEEE T. Geosci. Remote, 32, 598-615, 1994.

Dessler, A. E. and Yang, P.: The distribution of tropical thin cirrus clouds inferred from Terra MODIS data, J. Climate, 16, 12411247, 2003.

Fougnie, B., Bracco, G., Lafrance, B., Ruffel, C., Hagolle, O., and Tinel C.: PARASOL in-flight calibration and performance, Appl. Optics, 46, 5435-5451, 2007.

Fu, Q., Yang, P., and Sun, W.: An accurate parameterization of the infrared radiative properties of cirrus clouds for climate models, J. Climate, 11, 2223-2237, 1998.

Fu, Q., Hu, Y. X., and Yang, Q.: Identifying the top of the tropical tropospause layer from vertical mass flux analysis and CALIPSO lidar cloud observations, Geophys. Res. Lett., 34, L14813, doi:10.1029/2007GL030099, 2007.

Gao, B. C. and Kaufman, Y. J.: Selection of 1.375- $\mu$ m MODIS channel for remote sensing of cirrus clouds and stratospheric aerosols from space, J. Atmos. Sci., 52, 4231-4237, 1995.

Heymsfield, A. J. and Platt, C. M. R.: A parameterization of the particle size spectrum of ice clouds in terms of the ambient temperature and the ice water content, J. Atmos. Sci., 41, 846-855, 1984.

King, M. D., Kaufman, Y. J., Menzel, W. P., and Tanre, D.: Remotesensing of cloud, aerosol, and water-vapor properties from the moderate resolution imaging spectrometer (MODIS), IEEE T. Geosci. Remote, 30, 2-27, 1992.

Lee, J., Yang, P., Dessler, A. E., Gao, B. C., and Platnick, S.: Distribution and radiative forcing of tropical thin cirrus clouds, J. Atmos. Sci., 66, 3721-3731, 2009.

Mace, G. G., Zhang, Y., Platnick, S., King, M.D., Minnis, P., and Yang, P.: Evaluation of cirrus cloud properties from MODIS radiances using cloud properties derived from ground-based data collected at the ARM SGP site, J. Appl. Meteorol., 44, 221-240, 2005.

McFarquhar, G. M., Heymsfield, A. J., Spinhirne, J., and Hart, B.: Thin and subvisual tropopause tropical cirrus: Observations and radiative impacts, J. Atmos. Sci., 57, 1841-1853, 2000.

Meyer, K., Yang, P., and Gao, B.C.: Optical thickness of tropical cirrus clouds derived from the MODIS 0.66- and 1.375- $\mu \mathrm{m}$ channels, IEEE T. Geosci. Remote, 42, 833-841, 2004.

Min, Q., Yin, B., Li, S., Berndt, J., Harrison, L., Joseph, E., Duan, M., and Kiedron, P.: A high-resolution oxygen A-band spectrometer (HABS) and its radiation closure, Atmos. Meas. Tech., 7, 1711-1722, doi:10.5194/amt-7-1711-2014, 2014.

Minnis, P., Young, D. F., Weilicki, B. A., Sun-Mack, S., Trepte, Q. Z., Chen, Y., Heck, P. W., and Dong, X.: A global cloud database from VIRS and MODIS for CERES, Proc. SPIE 3rd Intl. AsiaPacific Environ, Remote Sensing Symp. 2002, Remote Sens. of 
Atmosphere, Ocean, Environment, and Space, Hangzhou, China, 23-27 October, 4891, 115-126, 2002.

National Oceanic and Atmospheric Administration, National Aeronautics and Space Administration, and United States Air Force: U.S. Standard Atmosphere, NOAA-S/T 76-1562, 1976.

Omar, A. H., Winker, D. M., Tackett, J. L., Giles, D. M., Kar, J., Liu, Z., Vaughan, M. A., Powell, K. A., and Trepte, C. R.: CALIOP and AERONET aerosol optical depth comparisons: One size fits none, J. Geophys. Res., 118, 4748-4766, doi:10.1002/jgrd.50330, 2013.

O’Dell, C. W., Connor, B., Bösch, H., O’Brien, D., Frankenberg, C., Castano, R., Christi, M., Eldering, D., Fisher, B., Gunson, M., McDuffie, J., Miller, C. E., Natraj, V., Oyafuso, F., Polonsky, I., Smyth, M., Taylor, T., Toon, G. C., Wennberg, P. O., and Wunch, D.: The ACOS CO2 retrieval algorithm - Part 1: Description and validation against synthetic observations, Atmos. Meas. Tech., 5, 99-121, doi:10.5194/amt-5-99-2012, 2012.

Packer, D. M. and Lock, C. : The brightness and polarization of the daylight sky at altitudes of 18,000 to 38,000 feet above sea level, J. Opt. Soc. Am., 41, 473-478, 1951.

Petty, G. W. and Huang, W.: The modified gamma size distribution applied to inhomogeneous and nonspherical particles: Key relationships and conversions, J. Atmos. Sci., 68, 1460-1473, 2011.

Rogers, R. R., Hostetler, C. A., Hair, J. W., Ferrare, R. A., Liu, Z., Obland, M. D., Harper, D. B., Cook, A. L., Powell, K. A., Vaughan, M. A., and Winker, D. M.: Assessment of the CALIPSO Lidar $532 \mathrm{~nm}$ attenuated backscatter calibration using the NASA LaRC airborne High Spectral Resolution Lidar, Atmos. Chem. Phys., 11, 1295-1311, doi:10.5194/acp-11-1295$2011,2011$.
Roskovensky, J. K. and Liou, K. N.: Detection of thin cirrus from $1.38 \mu \mathrm{m} / 0.65 \mu \mathrm{m}$ reflectance ratio combined with $8.6-11 \mu \mathrm{m}$ brightness temperature difference, Geophys. Res. Lett., 30, 1985, doi:10.1029/2003GL018135, 2003.

Sun, W. and Lukashin, C.: Modeling polarized solar radiation from the ocean-atmosphere system for CLARREO intercalibration applications, Atmos. Chem. Phys., 13, 10303-10324, doi:10.5194/acp-13-10303-2013, 2013.

Sun, W., Lin, B., Hu, Y., Lukashin, C., Kato, S., and Liu, Z.: On the consistency of CERES longwave flux and AIRS temperature and humidity profiles, J. Geophys. Res., 116, D17101, doi:10.1029/2011JD016153, 2011a.

Sun, W., Videen, G., Kato, S., Lin, B., Lukashin, C., and Hu, Y.: A study of subvisual clouds and their radiation effect with a synergy of CERES, MODIS, CALIPSO, and AIRS data, J. Geophys. Res., 116, D22207, doi:10.1029/2011JD016422, 2011 b.

Sun, W., Videen, G., and Mishchenko, M. I.: Detecting super-thin clouds with polarized sunlight, Geophy. Res. Lett., 41, 688-693, doi:10.1002/2013GL058840, 2014.

Virts, K. S., Wallace, J. M., Fu, Q., and Ackerman, T. P.: Tropical tropopause transition layer cirrus as represented by CALIPSO lidar observations, J. Atoms. Sci., 67, 3113-3129, 2010.

Winker, D. M., Hunt, W. H., and McGill, M. J.: Initial performance assessment of CALIOP, Geophys. Res. Lett., 34, L19803, doi:10.1029/2007GL030135, 2007.

Wylie, D. P. and Menzel, W. P.: Eight years of high cloud statistics using HIRS, J. Climate, 12, 170-184, 1999.

Wylie, D. P., Piironen, P., Wolf, W., and Eloranta, E.: Understanding satellite cirrus cloud climatologies with calibrated lidar optical depths, J. Atmos. Sci., 52, 4327-4343, 1995. 